\title{
"Discovery" Focus as Impetus for Organizational Learning
}

The University of Nevada Las Vegas Libraries' focus on the concept of discovery and the tools and processes that enable our users to find information began with an organizational review of the Libraries' Technical Services Division. This article outlines the phases of this review and subsequent planning and organizational commitment to discovery. Using the theoretical lens of organizational learning, it highlights how the emerging focus on discovery has provided an impetus for genuine learning and change.

$\mathrm{T}$ he University of Nevada Las Vegas (UNLV) Libraries' focus on the concept of discovery and the tools and processes that enable our users to find information stemmed from the confluence of several initiatives. However, a significant path that is directly responsible for the increased attention on discovery leads through one unit in UNLV Libraries-Technical Services. This unit, consisting of the Materials Ordering and Receiving (acquisitions) and Bibliographic and Metadata Services (cataloging) departments, had been without a permanent director for three years when I was asked to take the interim post in April 2008. While the initial expectation was that I would work with the staff to continue to keep Technical Services functioning while we performed our third search for a permanent director, it became clear after three months that, because of Nevada's budgetary limitations, we would not be able to go forward with a search at that time. As all personnel searches in UNLV Libraries were frozen, managers and staff across the divisions moved quickly to reassign staff with the aim of mitigating the effects of staff vacancies.

There was division between the library administrators as to what the solution would be for Technical Services: split up the division-for which we had trouble recruiting and retaining a leader in the past-and divvy up its functions among other divisions in the Libraries, or to continue to hold down the fort while conducting a review of Technical Services that would inform what it might become in the future. Other organizations have taken serious looks at, and provided roadmaps of, how their organizations' focus of technical services will change in the future. ${ }^{1}$ The latter route was chosen, and the review-eventually dubbed Revisioning Technical Services-led directly to the inquiries and activities documented in this ITAL special issue. Detailing the

Jennifer L. Fabbi (jennifer.fabbi@unlv.edu) is Special Assistant to the Dean at the University of Nevada Las Vegas Libraries.

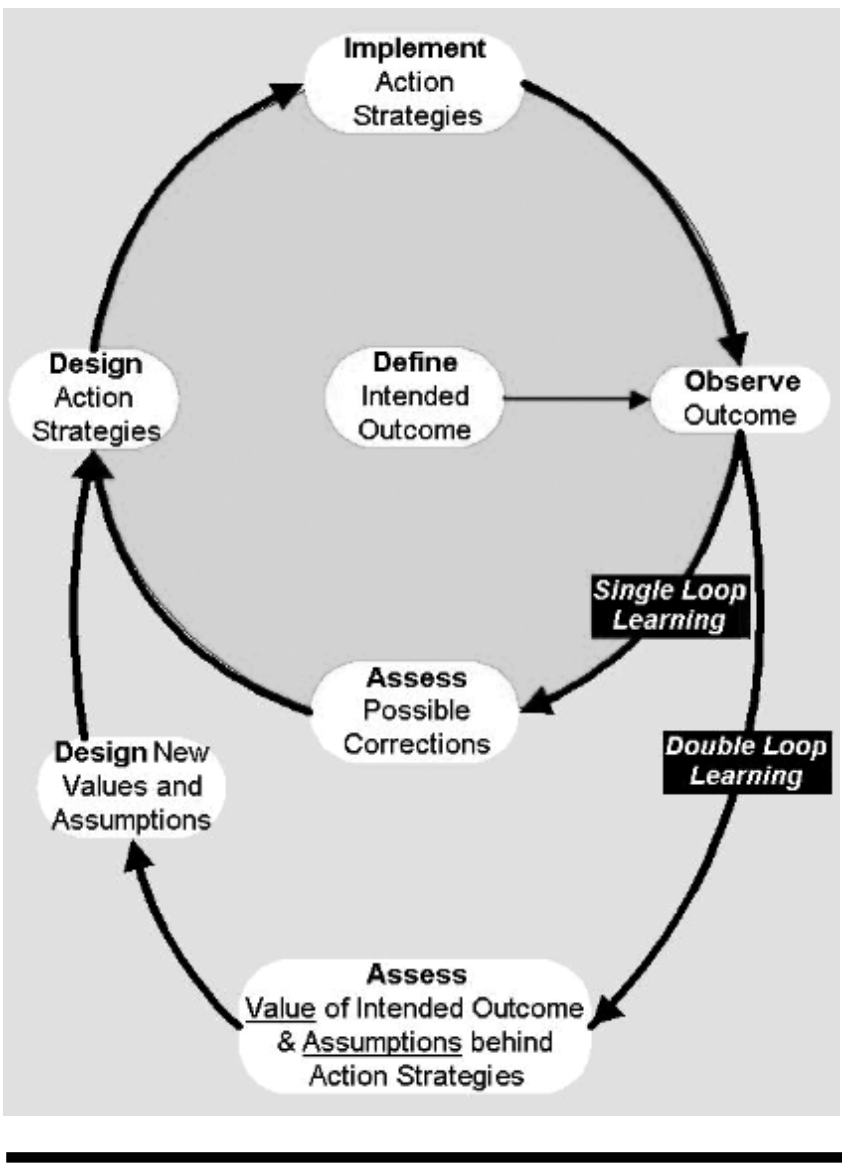

Figure 1. Single- and double-loop learning

Source: Learning-Org Discussion Pages, "Single and Double Loop Learning," Learning-Org Dialog on Learning Organizations, http://www.learning-org.com/ graphics/LO23374SingleDLL.jpg (accessed Aug. 11, 2009).

process of Revisioning Technical Services and using the theoretical lens of organizational learning, I will demonstrate how the Libraries' emerging focus on the concept of discovery has provided an impetus for genuine learning and change.

\section{Organizational learning}

In Images of Organization, Morgan devotes a chapter to theories of organizational development that characterize organizations using the metaphor of the brain. ${ }^{2}$ Based on the principles of modern cybernetics, Argyris and Schön provide a framework for thinking about how organizations can learn to learn. ${ }^{3}$ While many organizations have become adept at single-loop learning-the ability to scan the environment, set objectives, and monitor their own 
general performance in relation to existing operating norms-these types of systems are generally designed to keep the organization "on course." Double-loop learning, on the other hand, is a process of learning to learn, which depends on being able to take a "double look" at the situation by questioning the relevance of operating norms (see figure 1). Bureaucratized organizations have fundamental organizing principles, including management hierarchy and subunit goals that are seen as ends to themselves, which can actually obstruct the learning process. To become skilled in the art of double-loop learning, organizations must avoid getting trapped in singlelooped processes, especially those created by "traditional management control systems" and the "defensive routines" of organizational members. ${ }^{4}$

According to Morgan, cybernetics suggests that learning organizations must develop capacities that allow them to do the following: ${ }^{5}$

- Scan and anticipate change in the wider environment to detect significant variations by

- embracing views of potential futures as well as of the present and the past;

- understanding products and services from the customer's point of view; and

- using, embracing, and creating uncertainty as a resource for new patterns of development.

- Develop an ability to question, challenge, and change operating norms and assumptions by

- challenging how they see and think about organizational reality using different templates and mental models;

- making sure strategic development does not run ahead of organizational reality; and

$\checkmark$ developing a culture that supports change and risk taking.

- Allow an appropriate strategic direction and pattern of organization to emerge by

- developing a sense of vision, norms, values, limits, or "reference points" to guide behavior, including the ability to question the limits being imposed;

- absorbing the basic philosophy that will guide appropriate objectives and behaviors in any situation; and

a placing as much importance on the selection of the limits to be placed on behavior as on the active pursuit of desired goals.

UNLV Libraries' Revisioning Technical Services process and the resulting organizational focus on discovery is outlined below, and the elements identifying UNLV
Libraries as a learning organization throughout this process are highlighted (see appendix A).

\section{Revisioning Technical Services}

This review of Technical Services was a process consisting of several distinct steps over many months, and each step was informed by the data and opinions gained in the prior steps:

Phase 1: Technical Services Baseline, focusing on the nature of Technical Services work at UNLV Libraries, in the library profession, and factors that affect this work now and in the future

Phase 2: Organizational Call to Action, engaging the entire organization in shared learning and input

Phase 3: Summit on Discovery, shifting significantly away from Technical Services and toward the concept of discovery of information and the experience of our users

\section{Technical Services Baseline}

The first phase of the process, which I called the "Technical Services Baseline," included a face-to-face meeting with me and all Technical Services staff. We talked openly about the challenges that we faced, options on the table for the division and why I thought that taking on this review would be the best course to pursue, and goals of the review. Outcomes of the process were guided by the dean of libraries, were written by me, and received input from Technical Services staff, resulting in the following goals:

1. Collect input about the kinds of skills and leadership we would like to see in our new Technical Services director. (while creating these goals, we were given the go-ahead to continue our search for a new director).

2. Investigate the organization of knowledge at a broad level — what is the added value that libraries provide?

3. Increase overall knowledge of professional issues in technical services and what is most meaningful for us at UNLV.

4. Encourage Technical Services staff to consider current and future priorities.

After establishing these goals, I began to document information about the process on UNLV Libraries' staff website (figure 2) so that all staff could follow its progress. 


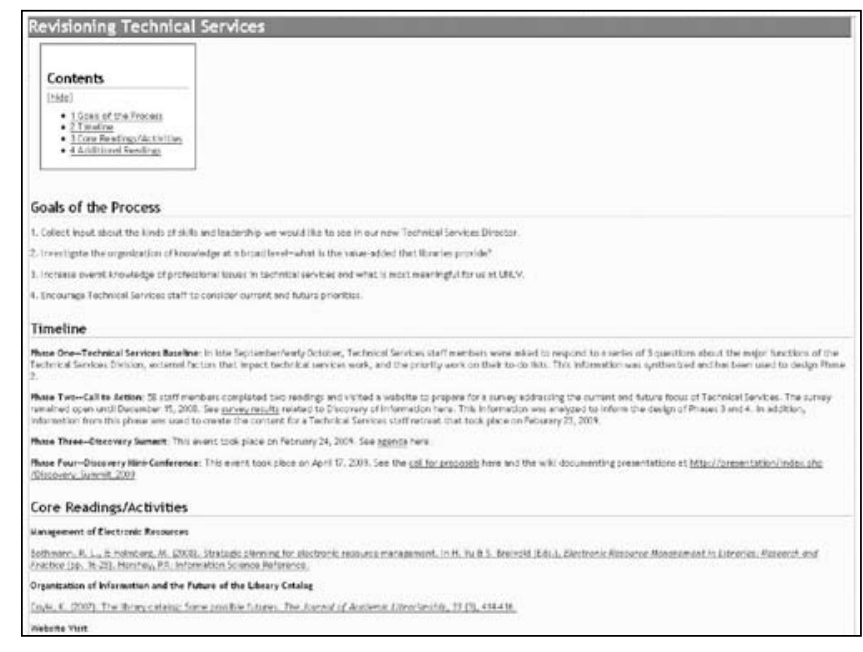

Figure 2. Project's wiki page on staff website

With the feedback I received at the face-to-face meeting and guided by the stated goals of the process, I gave Technical Services staff a series of three questions to answer individually:

1. What do you think the major functions of Technical Services are? Examples are "cataloging physical materials" and "ordering and paying for all resources purchased from the collections budget."

2. What external factors-in librarianship and otherwise-should we be paying the most attention to in terms of their effect on technical services work? Examples are "the ways that users look for information" and "reduction of print book and serials budgets." Feel free to do a little research on this question and provide the sources of the information that you find.

3. What are the three highest priority/most important tasks on your to-do list right now?

Eighteen of twenty staff members responded to the questions. I then analyzed the twenty pages of feedback according to two specific criteria: (1) I paid special attention to phrases that indicated an individual's beliefs, values, or philosophies to identify potential sources of conflict as we moved through the process; and (2) I looked for priority tasks listed that are not directly related to the individual's job duties, as many of them were indicators of work stress or anxiety related to perceived impending change.

During this phase, organizational learning was initiated through the process of challenging how Technical Services staff and others viewed Technical Services as a unit in the organization, and through the creation of shared reference points to guide our future actions. While beginning a dialogue about a variety of future management options for Technical Services work functions may have raised levels of anxiety within the organization, it also invited administration and staff to question the status quo and consider alternative modes of operation within the context of efficiency. ${ }^{6}$ In addition to thinking about current realities and external influences, staff were asked to participate in generating outcomes to guide the review process. These shared goals helped to develop a sense of coherence for what started out as a very loose assignment-a review that would inform what the unit might become in the future.

\section{Organizational Call to Action}

The next phase of the process, "A Call to Action," required library-wide involvement and input. While I knew that this phase would involve a library staff survey, I also desired that all staff responding to the survey had a basic knowledge of some of the issues that are facing library technical services today. Using input from the two Technical Services department heads, I selected two readings for all library staff: Bothmann and Holmberg's chapter on strategic planning for electronic resource management addressed many of the planning, policy, and workflow issues that UNLV Libraries has experienced7; and Coyle's article on information organization and the future of the library catalog offers several ideas for ensuring that valuable information is visible to our users in the information environments they are using. ${ }^{8}$ I also asked the library staff to visit the University of Nebraska-Lincoln's "Encore Catalog Search" (http://iris.unl.edu) and go through the discovery experience by performing a guided search and a search on a topic of their choice. They were then asked to ponder what collections of physical or digital resources we currently own at the Libraries that are not available from the library catalog.

After completing these steps, I directed library staff to a survey of questions related to the importance of several items referenced in the articles in terms of the following UNLV Libraries priorities:

- Creating a single search interface for users pulling together information from the traditional library catalog as well as other resources (e.g., journal articles, images, archival materials)

- Considering non-MARC records in the library catalog for the integration of nontraditional library and nonlibrary resources into the catalog

- Linking to access points for full-text resources from the catalog

- Creating ways for the catalog to recommend items to users 
- Creating metadata for materials not found in the catalog

- Creating "community" within the library catalog

- Implementing an Electronic Resource Management System (ERMS) to help manage the details related to subscriptions to electronic content

- Implementing federated searching so that users can search across multiple electronic resource interfaces at once

- Making electronic resource license information available to library staff and patrons

There also were several questions asking library staff to prioritize many of the functions that Technical Services already undertakes to some extent:

- Cataloging specialized or unique materials

- Cataloging and processing gift collections

- Ensuring that full-text electronic access is represented accurately in the catalog

- Claiming and binding print serials

- Ordering and receiving physical resources

- Ordering and receiving electronic resources

- Maintaining and communicating acquisitions budget and serials data

The survey asked Technical Services staff to "think of your current top three priority to-do items. In light of what you read and what you think is important for us to focus on, how do you think your work now will have changed in five years?" All other library staff members were asked to respond to the following:

1. Please list two ways that Technical Services supports your work now.

2. Please list two things you would like Technical Services to start doing in support of your work now.

3. Please list two things you think Technical Services can stop doing now.

4. Please list two things Technical Services will need to begin doing to support your work in the next five years.

Finally, the survey included ample opportunity for additional comments. Fifty-eight staff members (over half of all library staff) completed the readings, activity, and survey. I analyzed the information to inform the design of subsequent phases of Revisioning Technical Services. The dean of libraries' direct reports then reviewed the design. In addition, many library staff contributed additional readings and links to library catalogs and other websites to add to the Revisioning Technical Services staff webpage.

Throughout this phase, the organization was invited into the learning process through engagement with shared reference points, the ability to question the status quo, and the ability to embrace views of potential futures as well as of the present and the past. ${ }^{9}$ The careful selection of shared readings and activities created coherence among the staff in terms of thinking about the future, but these ideas also raised many questions about the concept of discovery and what route UNLV Libraries might take. The survey allowed library staff to better understand current practices in technical services, to prioritize new ideas against these practices, and to think about future options and their potential impact on their individual work as well as the collective work of the Libraries.

\section{Summit on Discovery}

In the third phase of this process, "The Discovery Summit," focus began to shift significantly from Technical Services as an organizational unit to the concept of discovery and what it means for the future of UNLV Libraries. During this half-day event, employing a facilitator from off campus, the dean of libraries and I designed a program to fulfill the following desired outcome: Through a process of focused inquiry, observation, and discussion, participants will more fully understand the discovery experience of UNLV Libraries users. The event was open to all library staff members; however, individuals were required to RSVP and complete an activity before the day of the event. (The facilitator worked specifically with the Technical Services staff at a retreat designed to prepare for upcoming interviews for Technical Services director candidates.)

Participants were each sent a "summit matrix" (see appendix B) ahead of time, which asked them to look for specific pieces of information by doing the following:

1. Search for the information requested with three discovery tools as your starting points: the Libraries' Catalog, the Libraries' website, and a general Internet search engine (like Google).

2. For each discovery tool, rate the information that you were able to find in terms of "ease of discovery" on a scale of 1 (lowest ease-few results) to 5 (highest ease-best results).

3. Document the thoughts and feelings you had and/ or process you went through in searching for this information.

4. Answer this question: Do you have other preferred starting points when looking for information that the Libraries own or provide access to?

The information that staff members were asked to search for using each discovery tool was mostly specific to the region of Southern Nevada, such as, "I heard that Henderson (a city in southern Nevada) started as a mining community. Does UNLV Libraries have any books about that?" and "Find any photograph of the gay 
pride parade in Las Vegas that you can look at in UNLV Libraries."

During the summit, the approximately sixty participants were asked to discuss their experiences searching for the matrix information, including any affective component to their experience, and they were asked to specify criteria for their definition of "ease of discovery." Next, we showed end-user usability video testing footage of a UNLV professor, a human resources employee, and a UNLV librarian going through similar discovery exercises. After each video, we discussed these users' experiences - their successes, failures, and frustrationsand the fact that even our experts were unable to discover some of this information. Finally, we facilitated a robust brainstorming session on initiatives we could undertake to improve the discovery experience of our users. [Editor's note: Read more about this usability testing in "Usability as a Method for Assessing Discovery" on page 181 of this issue.]

During the wrap-up of the Discovery Summit, the final phase of this initial process, the Discovery MiniConference was introduced. A call for proposals for library staff to introduce or otherwise present discovery concepts to other library staff was distributed. This call tied together the Revisioning Technical Services process to date and also placed the focus on discovery to the Libraries' upcoming strategic planning process. This strategic planning process, outlining broad directions for the Libraries to focus on for the next two years, would be the first time we would use our newly created evaluation framework. We focused on the concepts of discovery, access, and use, all tied together through an emphasis on the user. All library staff members were invited to submit a poster session or other visual display on various themes related to discovery of information to add to our collective and individual knowledge bases and to better understand our colleagues' philosophies and positions on discovery.

In addressing one of six Mini-Conference themes listed below, all drawn directly from the Revisioning Technical Services survey results, potential participants were asked to consider the question, "What are your ideas for ways to improve how users find library resources?"

- single search interface (federated searching, harvester-type platform, etc.)

- open source vs. vendor infrastructure

- information-seeking behavior of different users

- social networking and Web 2.0 features as related to discovery

- describing primary sources and other unique materials for discovery

- opening the library catalog for different record types and materials
Proposals could include any of these perspectives:

- an environmental scan with a summary of what you learn

- a visual representation of what you would consider improvement or success

- a position for a specific approach or solution that you advocate

Ultimately, we had seventeen distinct projects involving twenty-four staff members for the afternoon MiniConference. It was attended by approximately seventy additional staff members from UNLV Libraries as well as representatives from institutions who share our Innovative system. We collected feedback on each project in written form and electronically after the Mini-Conference. MiniConference content was documented on its own wiki pages and in this special issue of ITAL.

During this phase of the Revisioning Technical Services process, there was an emphasis on understanding our services from the customers' point of view, a hallmark of a learning organization. ${ }^{10}$ During the Discovery Summit, we aimed to transform frustration and uncertainty over the user experience of the services we are providing into a motivation to embrace potential futures. The Mini-Conference utilized the discovery themes that had evolved throughout the Revisioning Technical Services process to provide a cohesive framework for library staff members to share their knowledge and ideas about discovery systems and to question the status quo.

\section{Organizational ownership of discovery: Strategic planning and beyond}

Through the phases of the Revisioning Technical Services process outlined above, it should be evident how the concept of discovery, highlighted during the process, moved from being focused on Technical Services to being owned by the entire organization. While the vocabulary of discovery had previously been owned by pockets of staff throughout UNLV Libraries, it has now become a common lexicon for all. The Libraries' evaluation framework, which includes discovery, had set the stage for our upcoming organizational strategic plan. Just prior to the Discovery Summit, the dean of libraries' direct reports group began to discuss how it would create a strategic plan for the 2009-11 biennium. It became increasingly apparent how important a focus on discovery would be in this process, and that we needed to time our planning right, allowing the organization and ourselves time to become familiar with the potential activities we might commit to in this area before locking into a strategic plan. 
The dean's direct reports group first spent time crafting a series of strategic directions to focus on in the two-year time period we were planning for. Rather than give the organization specific activities to undertake, the strategic directions were meant to focus our new initiatives - and in a way to limit that activity to those that would move us past the status quo. Of the sixteen directions, one stemmed directly from the organization's focus on discovery: "Improve discoverability of physical and electronic resources in empowering users to be self sufficient; work toward an interface and system architecture that incorporates our resources, internal and external, and allows the user to access them from their preferred starting point." An additional direction also touched on the discovery concept: "Monitor and adapt physical and virtual spaces to ensure they respond to and are informed by next-generation technologies, user expectations, and patterns in learning, social interactions, and research collaboration; encourage staff to experiment with, explore, and share innovative and creative applications of technology."

Through their division directors and standing committees, all library staff members were subsequently given the opportunity to submit action items to the strategic plan within the framework of the strategic directions. The effort was made by the dean of libraries for this part of the process to coincide with the Discovery Mini-Conference, a time when many library staff members were being exposed to a wide variety of potential activities that we might take as an organization in this area. One of the major action items that made it into the strategic plan was for the dean's direct reports to charge an oversight task force with the investigation and recommendation of a systems or systems that would foster increased, unified discovery of library collections.

The charge of this newly created Discovery Task Force includes a set of guiding principles for the group in recommending a discovery solution that

- creates a unified search interface for users pulling together information from the library catalog as well as other resources (e.g., journal articles, images, archival materials);

- enhances discoverability of as broad a spectrum of library resources as possible;

- is intuitive: minimizes the skills, time, and effort needed by our users to discover resources;

- supports a high level of local customization (such as accommodating branding and usability considerations);

- supports a high level of interoperability (easily connecting and exchanging data with other systems that are part of our information infrastructure);
- demonstrates commitment to sustainability and future enhancements; and

- is informed by preferred starting points of the user.

In setting forth these guiding principles, the work of the Discovery Task Force is informed by the organization's discovery values, which have evolved over a year of organizational learning.

In the timing of the strategic planning process and the emphasis of the plan, we made sure that the organization's strategic development did not run ahead of organizational reality and also have worked to develop a culture that supports change and risk taking. ${ }^{11}$ The strategic discovery direction and pattern of organizational focus has been allowed to emerge throughout the organizational learning process. As evidenced in both the strategic plan directions and guiding principles laid out in the charge of the Discovery Task Force, the organization has begun to absorb the basic philosophy that will guide appropriate objectives in this area and has focused more on this guiding philosophy than on the active pursuit of one right answer as it continues to learn.

\section{Conclusion}

Using the theoretical lens of organizational learning, I have documented how UNLV Libraries' emerging focus on the concept of discovery has provided an impetus for learning and change (see appendix A). Our experience throughout this process supports the theory that organizational intelligence evolves over time and in reference to current operating norms. ${ }^{12}$ Argyris and Schön warn that a top-down approach to management focusing on control and clearly defined objectives encourages singleloop learning. ${ }^{13}$ Had UNLV Libraries chosen a more management-oriented route at the beginning of this process, it most likely would have yielded an entirely different result. In this case, genuine organizational learning proved to be action based and ever-emerging, and while this is known to introduce some level of anxiety into an organization, the development of the ability to question, challenge, and potentially change operating norms has been worth the cost. ${ }^{14} \mathrm{I}$ believe that while any single idea we have broached in the discovery arena may not be completely unique, it is the entire process of organizational learning that is significant and applicable to many information and technology-related areas of interest.

\section{References}

1. Karen Calhoun, The Changing Nature of the Catalog and its Integration with Other Discovery Tools (Washington, D.C.: Library 
of Congress, 2006), http:/ / www.loc.gov/catdir/calhoun-report -final.pdf (accessed Aug. 12, 2009); Bibliographic Services Task Force, Rethinking How We Provide Bibliographic Services for the University of California (Univ. of California Libraries, 2005), http://libraries.universityofcalifornia.edu/sopag/BSTF/Final .pdf (accessed Aug. 12, 2009).

2. Gareth Morgan, Images of Organization (Thousand Oaks, Calif.: Sage, 2006).

3. Chris Argyris and Donald A. Schön, Organizational Learning II: Theory, Method, and Practice (Reading, Mass.: Addison Wesley, 1996).

4. Morgan, Images of Organization, 87.

5. Morgan, Images of Organization, 87-97.

6. Ibid.
7. Robert L. Bothmann and Melissa Holmberg, "Strategic Planning for Electronic Management," in Electronic Resource Management in Libraries: Research and Practice, ed. Holly Yu and Scott Breivold, 16-28 (Hershey, Pa.: Information Science Reference, 2008).

8. Karen Coyle, "The Library Catalog: Some Possible Futures," The Journal of Academic Librarianship 33, no. 3 (2007): 414-16.

9. Morgan, Images of Organization.

10. Ibid.

11. Ibid.

12. Ibid.

13. Argyris and Schön, Organizational Learning II.

14. Morgan, Images of Organization.

\section{APPENDIX A. Tracking UNLV Libraries' Discovery Focus across Characteristics of Organizational Learning}

Scan and anticipate change in the wider environment to detect significant variations by

- embracing views of potential futures as well as of the present and the past (Revisioning Phase 1: Technical Services questions);

- understanding products and services from the customer's point of view (Revisioning Phase 3: Summit); and

- using, embracing, and creating uncertainty as a resource for new patterns of development (Revisioning Phase 1: Meeting; Phase 3: Summit).

Develop an ability to question, challenge, and change operating norms and assumptions by

- challenging how they see and think about organizational reality using different templates and mental models (Revisioning Phase 2: Survey);

- making sure strategic development does not run ahead of organizational reality (Strategic Planning process; Discovery Task Force charge); and
- developing a culture that supports change and risk taking (Strategic Planning process).

Allow an appropriate strategic direction and pattern of organization to emerge by

- developing a sense of vision, norms, values, limits, or "reference points" to guide behavior, including the ability to question the limits being imposed (Revisioning Phase 1: Outcomes; Phase 2: Shared readings, activity; Strategic Planning process; Discovery Task Force charge);

- absorbing the basic philosophy that will guide appropriate objectives and behaviors in any situation (Strategic Planning process, Discovery Task Force charge); and

- placing as much importance on the selection of the limits to be placed on behavior as on the active pursuit of desired goals (Strategic Planning process, Discovery Task Force charge). 


\section{APPENDIX B. Summit Matrix}

Please complete the following and bring to the Summit on Discovery-February 24:

1. Search for the information requested in each row of the table below with three discovery tools as your starting points: the Libraries Catalog, the Libraries Website, and a general Internet search engine (like Google).

2. For each discovery tool, rate the information that you were able to find in terms of "ease of discovery" on a scale of 1 (lowest ease) to 5 (highest ease).

3. Document the thoughts and feelings you had and/ or process you went through in searching for this information in the space provided.

4. Answer this question: Do you have other preferred starting points when looking for information that the Libraries own or provide access to?

\begin{tabular}{|c|c|c|c|c|}
\hline What am I looking for? & Libraries Catalog & Libraries Website & Google & $\begin{array}{l}\text { Thoughts, etc., on } \\
\text { what I discovered }\end{array}$ \\
\hline \multicolumn{5}{|l|}{$\begin{array}{l}\text { What's all the fuss about } \\
\text { Frazier Hall? Why is it } \\
\text { important? Does UNLV } \\
\text { Libraries have any } \\
\text { documents about the } \\
\text { history of the university } \\
\text { that reference it? }\end{array}$} \\
\hline \multicolumn{5}{|l|}{$\begin{array}{l}\text { It's Black History month } \\
\text { and my professor wants } \\
\text { me to find an oral } \\
\text { history about African } \\
\text { Americans in Las Vegas } \\
\text { that is available in UNLV } \\
\text { Libraries. }\end{array}$} \\
\hline \multicolumn{5}{|l|}{$\begin{array}{l}\text { I heard that Henderson } \\
\text { started as a mining } \\
\text { community. Does UNLV } \\
\text { Libraries have any books } \\
\text { about that? }\end{array}$} \\
\hline $\begin{array}{l}\text { Find any photograph of } \\
\text { the gay pride parade in } \\
\text { Las Vegas that you can } \\
\text { look at in UNLV Libraries. }\end{array}$ & & & & \\
\hline
\end{tabular}

